\title{
Faktor-Faktor Yang Mempengaruhi Keputusan Nasabah Untuk Menggunakan Jasa Perbankan Syariah Di Kota Tasikmalaya
}

\author{
Desiana, Dewi Susilowati, Negina Kencono Putri \\ Universitas Jenderal Soedirman \\ desianadesiana2@gmail.com,dew_suslow@yahoo.com negina_kp@yahoo.com
}

\begin{abstract}
This study aims to analyze the factors that influence the customers' decision in using Islamic banking in Tasikmalaya. This study uses a quantitative method. The data used in this study is primary data. Primary data was obtained from questionnaires distributed to a hundred customers of Islamic banking in Tasikmalaya. Analysis of data uses multiple linear regression and the results show that in partial the variable of profit sharing has significantly positive effect on the customers' decision to use islamic banking, the variable of religion quality has significantly positive effect on the customer's decision to use islamic banking, the variable of education has significantly positive effect on the customer's decision to use islamic banking,the variable of income doesn't have significantly positive effect on the customer's decision to use islamic banking and the variable of products and services have significantly positive effect on the customers' decision to use islamic banking in Tasikmalaya.

Keywords: Islamic Banking, Profit Sharing, Religion Quality, Education, Revenue, Product and Services, the Customer Decision
\end{abstract}

\begin{abstract}
Abstrak
Penelitian ini bertujuan untuk menganalisis faktor-faktor yang mempengaruhi keputusan pelanggan dalam menggunakan perbankan syariah di Tasikmalaya. Penelitian ini menggunakan metode kuantitatif. Data yang digunakan dalam penelitian ini adalah data primer. Data primer diperoleh dari kuesioner yang dibagikan kepada seratus nasabah perbankan syariah di Tasikmalaya. Analisis data menggunakan regresi linier berganda dan hasilnya menunjukkan bahwa secara parsial variabel profit sharing berpengaruh positif signifikan terhadap keputusan pelanggan menggunakan perbankan syariah, variabel kualitas agama berpengaruh positif signifikan terhadap keputusan pelanggan untuk menggunakan perbankan syariah., variabel pendidikan berpengaruh positif signifikan terhadap keputusan pelanggan untuk menggunakan perbankan islamic, variabel pendapatan tidak berpengaruh positif signifikan terhadap keputusan pelanggan untuk menggunakan perbankan islam dan variabel produk dan jasa berpengaruh positif signifikan terhadap keputusan konsumen untuk menggunakan perbankan syariah di Tasikmalaya.

Kata Kunci: Perbankan Syariah, Bagi Hasil, Kualitas Agama, Pendidikan, Pendapatan, Produk dan Layanan, Keputusan Pelanggan
\end{abstract}

Diterima: 4 Juni 2108; Revisi: 2018; Disetujui: 2018 


\section{PENDAHULUAN}

Kegiatan ekonomi adalah kegiatan yang tidak dapat terpisahkan dari kehidupan umat manusia. Salah satu organisasi yang melakukan kegiatan ekonomi di Indonesia adalah perbankan. Bank di Indonesia terbagi menjadi dua kategori, yaitu bank umum (konvensional) dan bank syariah. Di Indonesia perbankan Syariah muncul sejak dikeluarkannya Undang-Undang No. 7 Tahun 1992 tentang Perbankan, yang secara implisit telah membuka peluang kegiatan usaha perbankan yang memiliki dasar operasional bagi hasil. Perbankan Syariah di Indonesia, pertama kali beroperasi pada 1 Mei 1992.

Berdasarkan Undang-Undang tersebut bank dapat beroperasi berdasarkan prinsip-prinsip syariah yang memungkinkan kegiatan bank syariah menjadi lebih luas. Eksistensi bank syariah bahkan semakin diperkuat dengan adanya UndangUndang Nomor 23 Tahun 1999 tentang Bank Indonesia yang kemudian diubah menjadi Undang-Undang Nomor 3 Tahun 2004 (UU BI). Penetapan UndangUndang ini memungkinkan diterapkannya kebijakan moneter berdasarkan prinsip-prinsip syariah. Upaya pengembangan perbankan syariah di Indonesia sebenarnya bukan hanya merupakan konsekuensi yuridis Undang-Undang Perbankan dan Undang-Undang BI saja, akan tetapi merupakan bagian yang tidak terpisahkan dari upaya penyehatan sistem perbankan nasional yang bertujuan meningkatkan daya tahan perekonomian nasional.

Munculnya Undang-Undang Perbankan (1998) dan Undang-Undang BI menjadi era baru bagi perbankan syariah di Indonesia. Jumlah bank syariah tumbuh dari hanya satu bank umum syariah dan 78 Bank Perkreditan Rakyat Syariah (BPRS) pada tahun 1998 menjadi 12 bank umum syariah dan 22 unit usaha syariah pada tahun 2015. Sementara itu jumlah BPRS bertambah menjadi 162 BPRS pada tahun 2015.

Indonesia adalah negara dengan mayoritas penduduknya beragama Islam jumlah umat muslim di indonesia menurut sensus yang dilakukan oleh Badan Pusat Statistik pada tahun 2010 adalah sebesar 87,18\% dari total penduduk Indonesia yang berjumlah 237.641.334 jiwa (sumber: www.bps.go.id). Hal ini menjadi peluang yang cukup besar bagi perbankan syariah di Indonesia untuk 
terus tumbuh dan berkembang, namun demikian pada kenyataannya saat ini perkembangan perbankan syariah di Indonesia belum maksimal. Demikian pula dengan kota Tasikmalaya. Kota Tasikmalaya adalah salah satu kota sentra industri kerajinan (hand-craft) dan perdagangan di Jawa Barat yang saat ini sedang tumbuh dan berkembang dengan cukup pesat.

Berdasarkan data dari OJK jumlah pembiayaan yang diberikan oleh perbankan syariah di kota Tasikmalaya pada tahun 2015 yakni sebesar 1,681 triliun rupiah dari jumlah keseluruhan pembiayaan perbankan di kota Tasikmalaya sebesar 12,91 Triliun dan jumlah dana pihak ketiga perbankan syariah kota Tasikmalaya yakni sebesar 931 miliar rupiah dari jumlah keseluruhan dana pihak ketiga perbankan kota Tasikmalaya 8,14515 Triliun rupiah. Hal ini menjadi peluang yang sangat besar bagi industri perbankan untuk menawarkan jasa dan fasilitas perbankan, terutama perbankan syariah.

Setiap tindakan manusia dilandasi atas dasar suatu pilihan yang paling baik dan paling menguntungkan. Dengan demikian manusia bisa meningkatkan kehidupan ekonominya. Kata rasional memiliki arti pikiran atau pertimbangan yang logis atau masuk akal. Berdasarkan pertimbangan untung rugi, manusia bisa meningkatkan kehidupan ekonominya. Pertimbangan yang rasional dimulai dari suatu hal yang kecil sampai hal yang besar. Bagi hasil adalah suatu sistem pengolahan dana dalam perekonomian Islam yakni pembagian hasil usaha antara pemilik modal (shahibul maal) dan pengelola (Mudharib) (Antonio, 2001). Perbankan syariah yang beroperasi berdasarkan prinsip bagi hasil menonjolkan aspek keadilan dalam bertransaksi (Ghazali, 2007), dengan bagi hasil nasabah bank syariah akan lebih diuntungkan dan prinsip keadilan dari pembagian keuntungan akan terjamin. Hal ini sesuai dengan penelitian yang dilakukan oleh Daulay (2010) yang melakukan studi analisis pelayanan dan bagi hasil terhadap keputusan menabung nasabah pada bank syariah di Kota Medan. Hasil penelitian menunjukan bahwa secara bersama-sama terdapat pengaruh yang sangat signifikan pelayanan dan bagi hasil terhadap keputusan menabung nasabah pada Bank Syariah di Kota Medan Secara parsial variabel pelayanan dan bagi hasil 
berpengaruh positif dan signifikan terhadap keputusan menabung nasabah bank syariah di Kota Medan. Berdasarkan uraian diatas maka:

H1. Diduga sistem bagi hasil berpengaruh terhadap keputusan nasabah untuk menggunakan jasa bank syariah di Kota Tasikmalaya.

Sementara, religiusitas seringkali diidentikkan dengan keberagamaan. Bagi seorang Muslim, religiusitas dapat diketahui dari seberapa jauh pengetahuan, keyakinan, pelaksanaan dan penghayatan atas syariat Islam (Nashori dan Diana, 2002). Berdasarkan penelitian yang dilakukan oleh Almossawi (2001) mengemukakan bahwa keputusan nasabah dalam memilih bank syariah lebih didorong oleh faktor keagamaan melalui dukungan masyarakat pada ketaatan perbankan terhadap prinsip-prinsip Islam. Semakin tinggi tingkat religiusitas seseorang, maka akan semakin mengerti mengenai batasan-batasan halal haram akan riba dan akan semakin tunduk dan patuh terhadap aturan-aturan agamnya dan mendorong keputusannya untuk menggunakan perbankan syariah. Berdasarkan uraian diatas maka:

H2. Diduga kualitas keagamaan berpengaruh terhadap keputusan nasabah untuk menggunakan jasa bank syariah di Kota Tasikmalaya

Pendidikan adalah usaha sadar dan terencana untuk mewujudkan suasana belajar dan proses pembelajaran agar peserta didik secara aktif mengembangkan potensi dirinya untuk memiliki kekuatan spiritual keagamaan, pengendalian diri, kepribadian, kecerdasan, akhlak mulia, serta keterampilan yang diperlukan dirinya, masyarakat, bangsa dan negara. Berdasarkan penelitian yang dilakukan oleh Kaynak (2005) pendidikan memiliki pengaruh terhadap keputusan nasabah untuk menggunakan bank syariah. Latar belakang pendidikan merupakan salah satu faktor pendorong terhadap preferensi masyarakat dalam menggunakan jasa perbankan syariah. Pendidikan seseorang akan menentukan wawasan orang tersebut, sehingga mudah dalam menerima dan menyerap informasi mengenai perbankan syariah. Hal ini memberikan makna bahwa semakin luas pengetahuan seseorang maka orang tersebut memiliki pengetahuan lebih mengenai perbankan 
syariah yang akhirnya mendorong untuk menggunakan produk dan jasa dari perbankan syariah. Berdasarkan uraian diatas maka:

H3. Diduga pendidikan berpengaruh terhadap keputusan menggunakan jasa perbankan syariah di Kota Tasikmalaya.

Berdasarkan penelitian yang dilakukan oleh Kaynak (2005) dan Metawa dan Almossawi (1998) menyatakan bahwa alasan utama yang sangat mempengaruhi peralihan bank, dimana pelayanan yang lebih baik yang disediakan oleh bank pesaing, keuntungan yang lebih tinggi yang disediakan oleh bank lain, dan berbagai macam produk dan jasa yang ditawarkan. Produk dan jasa yang ditawarkan oleh perbankan syariah menjadi pendorong dalam memilih perbankan syariah. Semakin beragam dan semakin bersaingnya produk yang ditawarkan maka akan semakin menarik minat untuk menggunakan perbankan syariah. Berdasarkan uraian diatas maka:

H4. Diduga produk dan jasa yang ditawarkan berpengaruh terhadap keputusan nasabah untuk menggunakan jasa bank syariah di Kota Tasikmalaya.

\section{METODE}

Penelitian ini menggunakan metode atau pendekatan kuantitatif. Data yang digunakan dalam penelitian ini adalah data primer berupa angket kuesioner yang diberikan kepada nasabah perbankan syariah di Kota Tasikmalaya.

Populasi dalam penelitian ini adalah masyarakat yang memiliki rekening tabungan maupun deposito di bank syariah di Tasikmalaya. Yakni Bank Muamalat, Bank Rakyat Indonesia Syariah dan Bank BJB Syariah Populasi penelitian ini berjumlah 45.206 orang. Pengambilan sampel dalam penelitian ini menggunakan teknik probability sampling berupa disproportionate stratified random sampling. Penentuan besar sampel pada penelitian ini dengan menggunakan metode Slovin dan diperoleh nilai minimal sampel sebanyak 100 orang nasabah (dengan dengan 
$\alpha$ 10\%). Sampel sejumlah responden ditarik dari tiga (3) Bank Syariah di Kota Tasikmalaya sebagai berikut:

Tabel 1. Komposisi Sampel Bank Syariah Kota Tasikmalaya Tahun 2016

\begin{tabular}{lccc}
\hline $\begin{array}{c}\text { Jumlah Rekening di Bank } \\
\text { Syariah }\end{array}$ & Ni (Populasi) & fi = Ni & ni =fi.n \\
& & 0,53340 & $53,34=53$ \\
\hline Bank Muamalat & 24.113 & 0,34763 & $34,763=35$ \\
\hline BJB Syariah & 15.715 & 0,11896 & $11,896=12$ \\
\hline BRI Syariah & 5.378 & & 100 \\
\hline Populasi (N) & 45.206 & & \\
\hline
\end{tabular}

Sumber: Data Komposisi Sampel di 3 Bank Syariah Kota Tasikmalaya Tahun 2016, diolah.

Data dalam penelitian ini sebalum diuji dengan alat uji regresi akan diuji dengan alat uji asumsi klasik. Adapun model penelitian yang disusun dalam penelitian ini adalah:

$$
\begin{aligned}
\text { KeputusanNasabah }= & \alpha+\beta_{1} \text { BagiHasil }+\beta_{2} \text { KualitasKeagamaan }+\beta_{3} \text { Pendidikan }+ \\
& \beta_{4} \text { Pendapatan }+\beta_{5} \text { Produk }+\varepsilon
\end{aligned}
$$

Pengujian hipotesis secara statistik dilakukan dengan menggunakan uji t (t-test) dengan kriteria hipotesis diterima apabila secara statistik nilai sig. $<\alpha(0,05)$.

\section{HASIL DAN PEMBAHASAN}

Untuk mengetahui ketepatan model yang digunakan dapat dilihat dari tabel Anova sebagai berikut:

Tabel 2. Uji Ketepatan Model ANOVA

\begin{tabular}{clrrrr}
\hline \multirow{2}{*}{ Model } & Sum of Squares & df & \multicolumn{1}{c}{ Mean } & \multicolumn{1}{c}{ F } & \multicolumn{1}{c}{ Sig. } \\
\hline 1 & Reguare & & \\
\hline & Residual & 729,493 & 5 & 145,899 & 166,303 \\
& Total & 82,467 & 94 &, 877 & \\
& 811,960 & 99 & & \\
\end{tabular}

Dependent Variable: KeputusanNasabah 
Predictors: (Constant), BagiHasil, KualitasKeagamaan, Pendidikan, Pendapatan, Produk

Sumber: Data diolah

Berdasarkan output tersebut dapat diketahui bahwa nilai F-hitung sebesar 166,303. Adapun nilai F-tabel pada tingkat signifikansi 5\% dan degree of freedom (df1) sebesar k-1 atau (6-1=5) dan derajat bebas penyebut (df2) sebesar $n-k$ atau (100-6=94) adalah sebesar 2,31. Sementara nilai signifikansinya sebesar 0,000. Dengan demikian dapat disimpulkan bahwa model regresi linear berganda fit, atau dengan kata lain bahwa variabel independen secara simultan dapat memprediksikan dengan baik variable dependen secara signifikan.

Sementara, hasil pengolahan analisis regresi ditunjukkan pada Tabel 3. berikut:

Tabel 3. Analisis Regresi Linier Berganda

\begin{tabular}{|c|c|c|c|c|c|}
\hline \multirow[t]{2}{*}{ Model } & \multicolumn{2}{|c|}{$\begin{array}{c}\text { Unstandardized } \\
\text { Coefficients }\end{array}$} & \multirow{2}{*}{$\begin{array}{c}\begin{array}{c}\text { Standardized } \\
\text { Coefficients }\end{array} \\
\text { Beta } \\
\end{array}$} & \multirow[t]{2}{*}{$\mathrm{t}$} & \multirow[t]{2}{*}{ Sig. } \\
\hline & $\mathrm{B}$ & Std. Error & & & \\
\hline (Constant) & 5,520 & 1,218 & & 4,533 & 0,000 \\
\hline Bagi Hasil & 0,927 & 0,119 & 0,650 & 7,820 & $0,000 *$ \\
\hline Kualitas Keagamaan & 0,149 & 0,074 & 0,129 & 1,999 & 0,049* \\
\hline 1 Pendidikan & 0,453 & 0,224 & 0,094 & 2,024 & $0,046^{*}$ \\
\hline Pendapatan & 0,127 & 0,217 & 0,034 & 0,586 & 0,559 \\
\hline Produk & 0,245 & 0,098 & 0,154 & 2,499 & $0,014^{*}$ \\
\hline
\end{tabular}

Dependent Variable: Keputusan Nasabah

Sumber: Data diolah

Model regresi yang dibentuk dari hasil uji statistik adalah sebagai berikut:

KeputusanNasabah $=5,520+$ 0,927BagiHasil + 0,149KualitasKeagamaan + 0,453Pendidikan + 0,127Pendapatan $+0,245$ Produk $+\varepsilon$

Berdasarkan output diketahui nilai sig. untuk variabel Bagi Hasil, Kualitas Keagamaan, Pendidikan dan Produk yang ditawarkan berturut-turut sebesar 0,$000 ; 0,049 ; 0,046 ; 0,014$ sehingga dapat disimpulkan bahwa hipotesis 1,2, 3 dan 5 dalam penelitian ini diterima. Sementara, variabel Pendapatan memiliki nilai sig sebesar 0,559 sehingga dapat disimpulkan bahwa hipotesis 4 dalam penelitian ini ditolak. 
Hasil dari penelitian ini menunjukan bahwa nasabah bank syariah di Kota Tasikmalaya melihat bagi hasil sebagai alasan keputusan menggunakan jasa perbankan syariah,. Hal ini sesuai dengan penelitian Marimuthu, et. al (2010) serta Ahmad dan Haron (2001) dimana keuntungan memegang peranan penting dalam peralihan penggunaan pelayanan jasa bank.

Sementara, dari hasil penelitian ditemukan bahwa kualitas keagaamaan seseorang berpengaruh signifikan terhadap keputusan menggunakan perbankan syariah. Disamping itu, latar belakang pendidikan merupakan salah satu faktor pendorong terhadap preferensi masyarakat dalam menggunakan jasa perbankan syariah. Pendidikan seseorang akan menentukan wawasan orang tersebut, sehingga mudah dalam menerima dan menyerap informasi mengenai perbankan syariah. Hal ini memberikan makna bahwa semakin luas pengetahuan seseorang maka orang tersebut memiliki pengetahuan lebih mengenai perbankan syariah yang akhirnya mendorong untuk menggunakan produk dan jasa dari perbankan syariah. Hasil dari penelitian ini menunjukan bahwa keputusan menggunakan jasa perbankan syariah juga dipengaruhi oleh pendidikan nasabah tersebut dimana berdasarkan pendidikan yang mereka perolehlah mendorong untuk menggunakan jasa perbankan syariah.

Menurut Kotler (1999), keputusan pembelian adalah tahap penilaian keputusan menyebabkan konsumen membentuk pilihannya di antara beberapa merk yang tergabung dalam perangkat pilihan. Pengharapan konsumen dibentuk berdasarkan pengalaman konsumen itu sendiri, saran teman-teman dan iklan yang disampaikan perusahaan jasa. Konsumen memilih membeli jasa berdasarkan pengharapan ini. Proses sebelum sampai kepada keputusan membeli konsumen menjalani tahapan proses pengambilan keputusan. Pada tahap ini konsumen mempelajari terlebih dahulu kelebihan dan kekurangan suatu produk. Produk dan jasa yang ditawarkan oleh perbankan syariah mempengaruhi keputusan nasabah untuk menggunakan jasa perbankan syariah. Dimana nasabah akan mempelajari terlebih dahulu kelebihan dan kekurangan produk tersebut sebelum memutuskan untuk menggunakannya. Hasil dari penelitian ini sesuai dengan penelitian yang dilakukan oleh Marimuthu et,al (2010) yang menyatakan bahwa alasan utama 
yang sangat mempengaruhi peralihan bank, dimana pelayanan yang lebih baik yang disediakan oleh bank pesaing, keuntungan yang lebih tinggi yang disediakan oleh bank lain, dan berbagai macam produk dan jasa yang ditawarkan. Penelitian ini juga menguatkan penelitian sebelumnya dimana produk yang ditawarkan oleh perbankan syariah menjadi faktor yang mendorong untuk menggunakan perbankan syariah, oleh karenanya perbankan syariah dituntut untuk menawarkan produk yang berkualitas.

Variabel pendapatan tidak berpengaruh signifikan terhadap keputusan nasabah menggunakan jasa perbankan syariah. Hasil dari penelitian ini menunjukan bahwa pendapatan tidak berpengaruh secara signifikan terhadap keputusan menggunakan jasa perbankan syariah. Besar kecilnya pendapatan tidak mempengaruhi secara signifikan terhadap keputusan menggunakan jasa perbankan syariah. Dari pengumpulan data yang dilakukan oleh peneliti, ditemukan bahwa nasabah yang datang ke perbankan syariah di Kota Tasikmalaya berasal dari berbagai kalangan dengan jumlah pendapatan yang beragam. Nasabah perbankan syariah tidak hanya berasal dari masyarakat yang memiliki pendapatan tinggi saja atau rendah saja tetapi dari berbagai kalangan dengan jumlah pendapatan yang berbeda-beda.

\section{SIMPULAN}

Berdasarkan penelitian tentang analisis faktor-faktor yang mempengaruhi keputusan nasabah dalam menggunakan produk dan jasa perbankan syariah maka diperoleh kesimpulan bahwa variabel nisbah Bagi Hasil, Kualitas Keagamaan, Pendidikan, dan Produk yang ditawarkan berpengaruh positif signifikan terhadap keputusan nasabah menggunakan jasa perbankan syariah.

Penelitian ini memiliki keterbatasan berupa responden dalam penelitian ini hanya berasal dari tiga cabang utama bank syariah yang ada di Kota Tasikmalaya. Penelitian selanjutnya diharapkan dapat memperluas cakupan responden. Selain itu dapat diteliti variabel-variabel lain yang berpengaruh terhadap keputusan nasabah untuk menggunakan produk dan jasa perbankan syariah. Penelitian 
selanjutnya dapat juga menggunakan kuesioner yang disebarkan melalui email ataupun menggunakan kuesioner dalam versi online.

\section{PUSTAKA ACUAN}

Ahmad, N dan Haron, S. 2001. Perception of Malaysian Corporate Customers Toward Islamic Banking Products \& Services, International Journal of Islamic Financial Service, Vol. 3 No. 4.

Almossawi, M. 2001. Bank selection criteria employed by college students in Bahrain: an emperical analysis, International Journal of Bank Marketing, Vol.19 No. 3, pp 115.

Antonio, Muhammad Syafi'i. 2001. Bank Syariah: Dari Teori ke Praktik. Jakarta : Gema Insani Press

Badan Pusat Statistik Kota Tasikmalaya. 2013. Jumlah Penduduk Menurut Kelompok Umur dan Jenis Kelamin di Kota Tasikmalaya tahun 2013. dalam www.tasikmalayakota.bps.go.id

Badan Pusat Statistik Kota Tasikmalaya. 2014. Luas Wilayah Menurut Kecamatan di Kota Tasikmalaya 2014 dalam www.tasikmalayakota.bps.go.id

Bank Indonesia. 2001. Potensi, Preferensi dan Perilaku Masyarakat terhadap Bank Syariah di Sumatera Barat. Jakarta dalam www.bi.go.id

Bank Indonesia. 2008. Statistik Perbankan Syariah (Islamic Banking Statistic) bulan November 2008. Jakarta: Direktorat Perbankan Syariah. dalam www.bi.go.id

Bank Indonesia. 2012. Statistik Perbankan Syariah (Laporan Perkembangan Perbankan Syariah tahun 2012). Jakarta dalam www.bi.go.id

BPS Kota Tasikmalaya. 2015. Kota Tasikmalaya Dalam Angka Tahun 2015. Tasikmalaya 
Daulay, Raihanah (2010). Analisis Pelayanan dan Bagi Hasil terhadap Keputusan Menabung Nasabah padaBank Syariah di Kota Medan. Jurnal Manajemen dan Bisnis vol 10 no. 01

Ghozali, Imam. 2007. Manajemen Risiko Perbankan. Semarang : BPUNDIP

Kaynak, E. 2005. American consumers' attitudes towards commercial banks,International Journal of Bank Marketing, Vol.23, No. 1.

Kotler, 1999, Manajemen Pemasaran, Analisis, Perencanaan, Implementasi dan Pengendalian, Jilid 2 Edisi kesembilan. Jakarta:Salemba Empat.

Marimuthu, M. et.al. 2010. Islamic Banking: Selection Criteria and Implications. GJHSS Classification Vol 10 Issue 4.

Metawa, S. A., \& Almossawi, M. 1998. Banking behavior of Islamic bank customers: Perspectives and implications, International of Bank Marketing, Vol. 16,No. 7.

Muhammad, 2006.Teknik Perhitungan Bagi Hasil dan Profit Margin pada Bank Syariah ,Yogyakarta : UII Press

Nashori, Fuad dan Rachmy Diana Mucharam. 2002. Mengembangkan Kreativitas dalam Perspektif Psikologi Islam. Jogyakarta: Menara Kudus.

Otoritas Jasa Keuangan. 2015. Statistik Perbankan Syariah April 2015 dalam www.ojk.go.id

\section{Undang-Undang}

Undang-Undang Republik Indonesia No.7 tahun 1992 tentang Perbankan

Undang-Undang No. 10 tahun 1998 tentang Perbankan yang mengakomodasi adanya dual banking system di Indonesia 
Undang-Undang No. 23 tahun 1999 tentang Perubahan Undang-undang Republik Indonesia No.10 tahun 1998

Undang-Undang No. 3 tahun 2004 tentang Perubahan Undang-undang Republik Indonesia No.23 tahun 1999

Undang-Undang No. 21 tahun 2008 tentang Perbankan Syariah

Undang-Undang Nomor 20 Tahun 2003 tentang Sistem Pendidikan Nasional 